02

\title{
Фотолюминесценция политетрафторэтилена в ближней инфракрасной области спектра
}

\author{
(c) В.М. Киселев ${ }^{1}$, И.В. Багров ${ }^{1}$, А.М. Стародубцев ${ }^{1}$, Н.Г. Гоголева ${ }^{2}$ \\ ${ }^{1}$ Государственный оптический институт им. С.И. Вавилова, \\ 199034 Санкт-Петербург, Россия \\ ${ }^{2}$ Санкт-Петербургский государственный электротехнический университет „лЭТИ“ имени В.И. Ульянова (Ленина), \\ 197376 Санкт-Петербург, Россия \\ e-mail: kiselevvm21@gmail.com
}

Поступила в редакцию 16.08.2021 г.

В окончательной редакции 31.08.2021 г.

Принята к публикации 31.08.2021 г.

Исследована фотолюминесценция политетрафторэтилена (фторопласта-4, также известного под торговой маркой тефлон) в ближней инфракрасной области спектра при его возбуждении ультрафиолетовым и видимым излучением. Показано, что в спектре фотолюминесценции, наблюдаемой с поверхности фторопласта при его возбуждении, отчетливо присутствует характерный профиль люминесценции, совпадающий по своему положению со спектром фосфоресценции синглетного кислорода.

Ключевые слова: фотолюминесценция, фосфоресценция, политетрафторэтилен, тефлон, фторопласт, синглетный кислород, оптическое возбуждение, светодиодные матрицы.

DOI: $10.21883 /$ OS.2021.12.51741.2648-21

\section{Введение}

В последние годы наблюдается активный рост интереса к перфторированным материалам. Благодаря своим уникальным физическим и химическим свойствам перфторированные материалы постоянно находят все новые области применения. Высокая растворимость кислорода, азота, углекислого газа и ряда других газов в перфторуглеродах и отличные токсикологические их свойства способствовали широким медицинским применениям перфторированных материалов в качестве кровезаменителей, при исцелении ран, в глазной хирургии, жидкостной вентиляции легких, кожной реабилитации, а также в качестве элемента для доставки сенсибилизирующего лекарственного средства к пораженной ткани в фотодинамической терапии [1-4].

Большой интерес при этом наблюдается и к исследованиям фотолюминесценции политетрафторэтилена (ПТФЭ) [5-9] при возбуждении образцов излучением в ультрафиолетовом и видимом спектральных диапазонах. Исследуемые образцы при возбуждении, как правило, демонстрируют широкий спектр излучения фотолюминесценции, простирающийся от фиолетовой до красной области спектра. Было также показано, что концентрация молекулярного кислорода в образце ПТФЭ играет ключевую роль в формировании оптического излучения фотолюминесценции [6,7]. Содержание кислорода в образце ПТФЭ, как показано в работе [10], может достигать до 6 wet.\%, многократно увеличиваясь при различных активных воздействиях на образец в виде $\gamma$ облучения [7] или потока электронов [10]. Параметры высокой сорбции и растворимости легких газов, в част- ности $\mathrm{O}_{2}, \mathrm{~N}_{2}, \mathrm{CO}_{2}$ идр., в перфторуглеродах авторами работы [11], которые провели измерения сорбции для двух образцов тефлона AF1600 и AF2400, связываются с исключительно высоким свободным объемом этих материалов, определяющим высокую объемную сорбцию различных видов газов.

В то же время надо отметить, что при достаточно активном исследовании фотолюминесценции ПТФЭ в ряде работ [5-9] все эти исследования были проведены только для видимой области спектра. Фотолюминесценция в инфракрасном (ИК) диапазоне и, в частности, в ближнем ИК диапазоне оказалась вне интересов этих исследований. В данной работе авторы попытались частично восполнить этот пробел, выполнив измерения фотолюминесценции ПТФЭ в оптическом диапазоне от 0.9 до $1.7 \mu \mathrm{m}$.

\section{Материалы и методика эксперимента}

При проведении исследований фотолюминесценции ПТФЭ в качестве исследуемых образцов использовались пленки фтороплата-4 толщиной 0.05 и $0.2 \mathrm{~mm}$ и пластины толщиной от 1 до $6 \mathrm{~mm}$ производства России, образец ПТФЭ производства Japan, а также порошковый образец фторопласта с размерами частиц $1-3 \mu \mathrm{m}$ (China).

В качестве источников оптического возбуждения ПТФЭ использовались светодиодные матрицы $(26 \times 26 \mathrm{~mm})$ серии HPR40Е с длинами волн излучения $\lambda_{m}=370,405,465,525$ и $625 \mathrm{~nm}$ и с $\Delta \lambda_{0.5}=20 \mathrm{~nm}$. Подводимая электрическая мощность для светодиодных матриц равна $100 \mathrm{~W}$. Параметры излучения светодиодных матриц представлены в таблице. Измерение мощности 

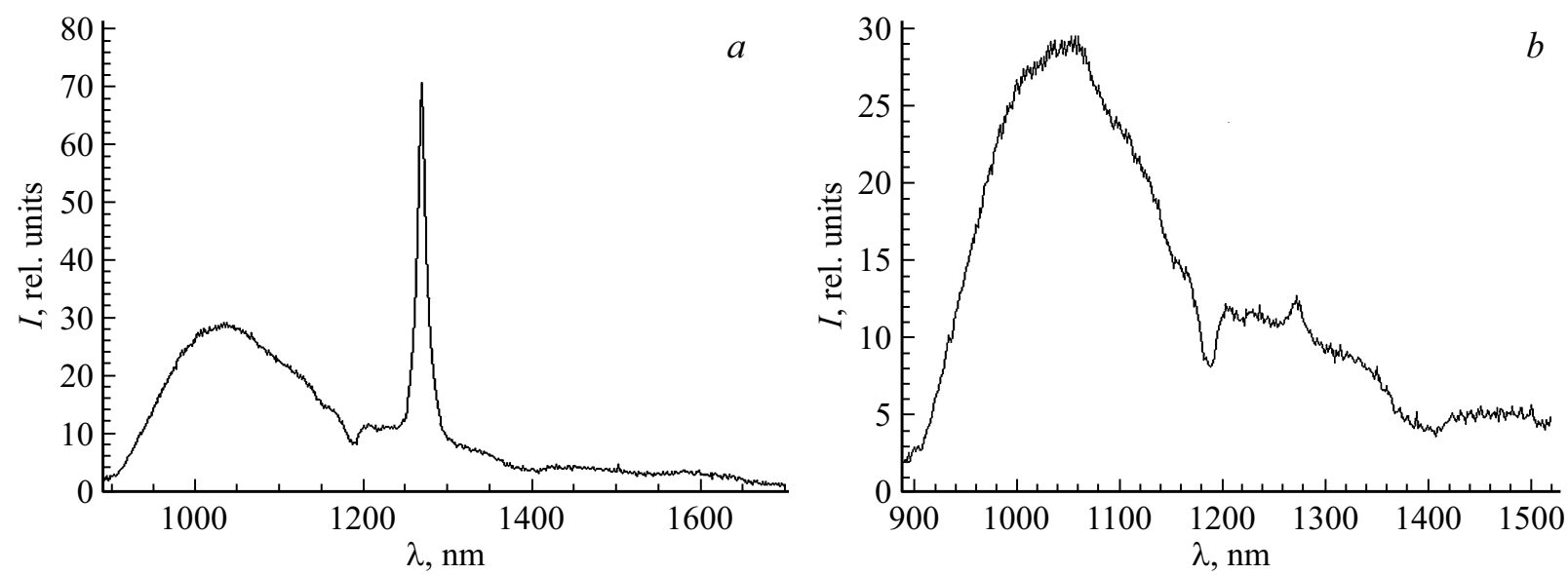

Рис. 1. Спектр фотолюминесценции ПТФЭ в ближнем ИК диапазоне для образца в виде пластины $(a)$ и для порошкообразного образца $(b)$.

излучения светодиодных источников осуществлялось измерителем мощности излучения Coherent-Molectron PS-10.

Регистрация излучения фотолюминесценции с поверхности исследуемых образцов ПТФЭ выполнялась с применением ИК спектрометра SDH-IV с приемной InGaAs-линейкой фирмы Hamamatsu (Япония), выпускаемого фирмой „Солар Лазерные Системы“ (Беларусь). Спектральный диапазон прибора от 868 до $1700 \mathrm{~nm}$. Применявшаяся схема эксперимента со светодиодной оптической накачкой для исследуемых образцов представлена в [12].

\section{Результаты эксперимента и их обсуждение}

Прежде чем переходить к анализу результатов исследования фотолюминесценции ПТФЭ, следует отметить спектральные свойства данного материала и прежде всего спектр поглощения оптического возбуждения. Характерные для образцов ПТФЭ спектры поглощения, пропускания и отражения довольно детально исследованы в работах [13-15], в которых показано, что ПТФЭ имеет низкие свойства поглощения в применяемом в настоящей работе диапазоне оптического возбуждения. Большая часть света диффузно отражается (от 90 до 95\%), и лишь небольшая часть проходит через материал (от 7 до 2\%). На поглощение приходится от 2 до 4\% в зависимости от толщины образца. При этом данная величина поглощения несущественно меняется в пределах указанного диапазона длин волн от 300 до $500 \mathrm{~nm}$.

Спектральные профили фотолюминесценции ПТФЭ для образца в виде пластины фторопласта-4 толщиной $3 \mathrm{~mm}(a)$ и для образца в виде порошка $(b)$ при возбуждении излучением на длине волны $370 \mathrm{~nm}$ представлены на рис. 1. Время экспозиции $12 \mathrm{~s}$. Как видно на представленном рисунке, наряду с широким
Параметры излучения светодиодных матриц

\begin{tabular}{c|c|c|c|c|c}
\hline$\lambda_{m}, \mathrm{~nm}$ & 370 & 405 & 480 & 525 & 625 \\
\hline$P, \mathrm{~W} / \mathrm{cm}^{2}$ & 0.35 & 1.0 & 1.8 & 0.60 & 1.0
\end{tabular}

спектром фотолюминесценции с максимумом в районе $1.035 \mu \mathrm{m}$ на общем спектральном профиле присутствует и характерный максимум люминесценции, совпадающий по своему положению со спектром фосфоресценции синглетного кислорода на длине волны $1270 \mathrm{~nm}$ (переход $\left.{ }^{1} \Delta_{g}\left(v^{\prime}=0\right)^{-3} \Sigma_{g}\left(v^{\prime \prime}=0\right)\right)$. Этот максимум достаточно отчетливо представлен для пластины и весьма слабо для порошкообразного образца.

Надо заметить, что спектральный профиль люминесценции для порошкообразного образца ПТФЭ очень сильно напоминает аналогичные результаты, которые ранее наблюдались для порошкообразных образцов оксидов металлов [16-18]. Как известно [16], эти результаты были связаны с прямым возбуждением кислорода, сорбированного на поверхности порошкообразных образцов. Наработка ${ }^{1} \mathrm{O}_{2}$ возрастала с уменьшением размеров частиц оксида металла вследствие увеличения их общей эффективной поверхности и соответствующего повышения за счет этого поверхностной сорбции газов. Таким образом, для порошкообразного образца ПТФЭ в данном случае, как и для оксидов металлов, наблюдается наработка синглетного кислорода в основном только за счет поверхностной сорбции газа. Тогда как для плотно упакованного образца ПТФЭ в виде пластины или пленки имеет место уже отмеченная ранее [11] высокая объемная сорбция газов с содержанием кислорода в объеме образца до 6 wet.\% [10]. По-видимому, именно поэтому интенсивность максимума люминесценции синглетного кислорода для пластины, как видно на рис. 1, $a$, много выше.

Интенсивность этого максимума для пластины зависит как от длины волны возбуждающего излучения, так 

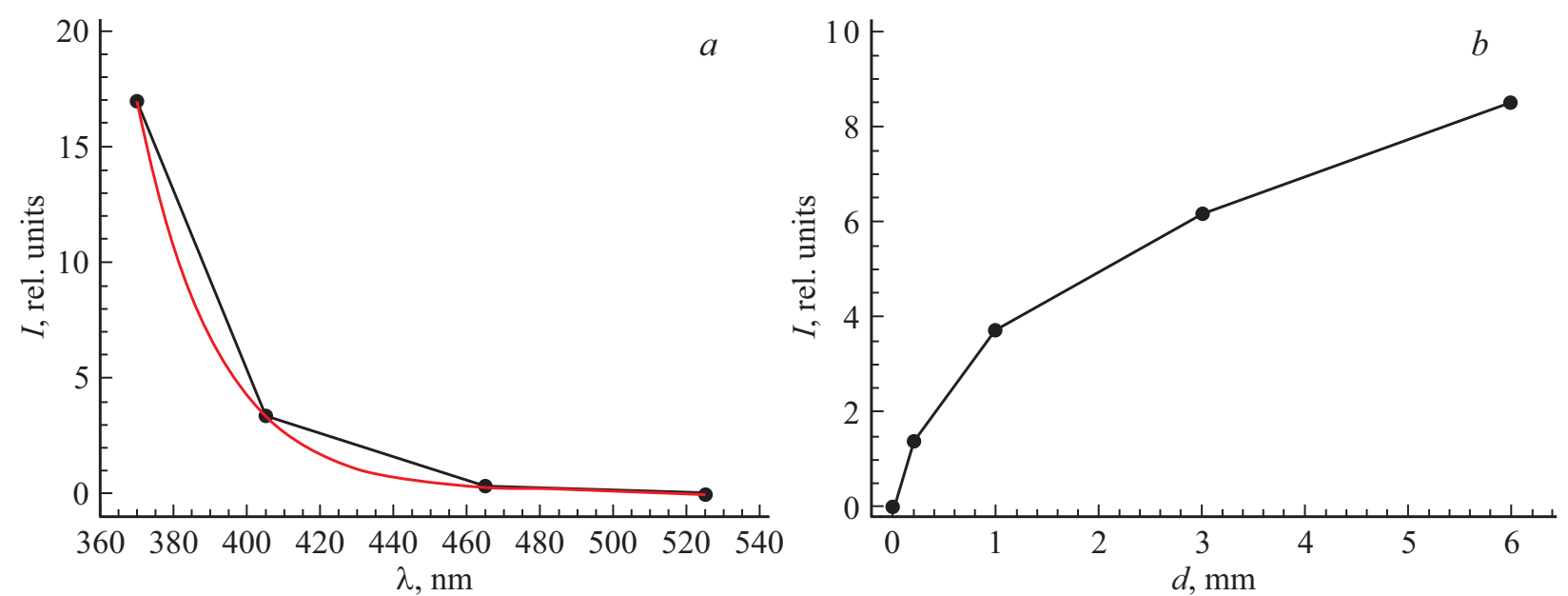

Рис. 2. Зависимость интенсивности фосфоресценции синглетного кислорода от длины волны излучения оптического возбуждения $(a)$ и от толщины образца $(b)$.

и от толщины облучаемого образца. Соответствующие зависимости представлены на рис. 2.

На рис. 2, $a$ показаны значения интенсивностей в максимуме спектрального профиля люминесценции, отнесенные к плотности мощности светового потока на выходе конкретной светодиодной матрицы. Эти приведенные относительные интенсивности демонстрируют определенную закономерность зависимости эффективности генерации синглетного кислорода от длины волны возбуждающего излучения. На рис. $2, b$ показаны значения интенсивностей в максимуме спектрального профиля люминесценции синглетного кислорода в зависимости от толщины образца ПТФЭ.

Представленные на рис. 2 зависимости нуждаются в дополнительных пояснениях относительно механизма активной генерации синглетного кислорода при облучении образца ПТФЭ в виде пластины или пленки излучением оптического возбуждения. Экспоненциальный спад интенсивности наработки синглетного кислорода при увеличении длины волны оптического возбуждения, с одной стороны, совершенно не коррелирует с кривой поглощения ПТФЭ, отмеченной выше, а с другой стороны, неплохо совпадает со спектральной зависимостью эффективности наработки синглетного кислорода при его прямом возбуждении, например, в растворе тетрахлорметана, приведенной в работах $[19,20]$. А как утверждается в ряде работ $[6,10]$, кислород может быть эффективно растворен в объеме ПТФЭ, и, следовательно, можно предположить, что в данном случае также возможно прямое возбуждение этого растворенного кислорода по аналогии с другими растворами, учитывая низкие свойства поглощения самого ПТФЭ в данном спектральном диапазоне излучения оптического возбуждения [15].

Зависимость интенсивности фосфоресценции синглетного кислорода от толщины образца, представленная на рис. $2, b$, опять же свидетельствует об объемном

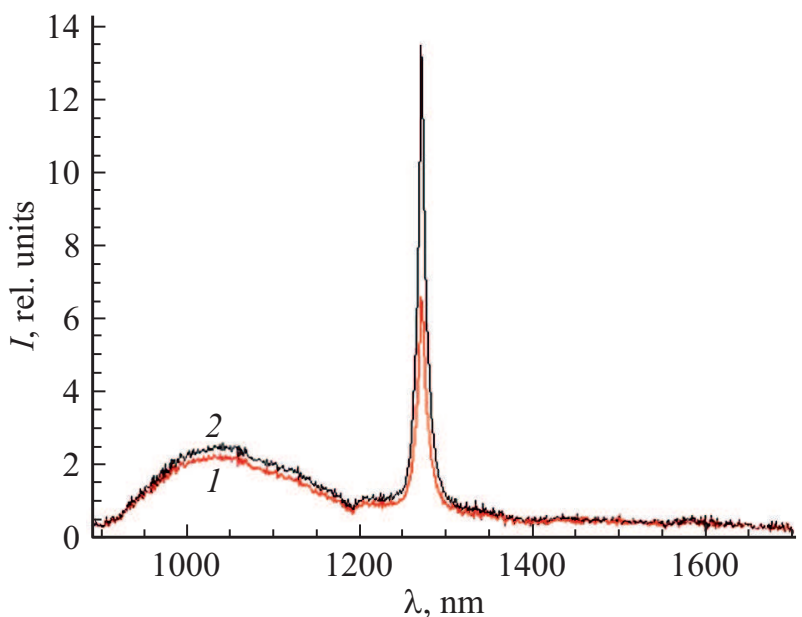

Рис. 3. Спектр фотолюминесценции синглетного кислорода из объема образца ПТФЭ (пластина толщиной $3 \mathrm{~mm}$ ) при комнатной температуре $25^{\circ} \mathrm{C}(1)$ и при охлаждении образца до $-20^{\circ} \mathrm{C}(2)$.

механизме наработки синглетного кислорода, подтверждая в определенной степени предположение о прямом возбуждении кислорода, растворенного в объеме полимера. При этом надо отметить и очень низкие значения поглощения и диффузного рассеяния излучения в ИК диапазоне в районе $1200-1600 \mathrm{~nm}$, измеренные нами с применением спектрофотометра Shimadzu-3600, которые позволяют излучению синглетного кислорода выходить из объема образца ПТФЭ без больших потерь в интенсивности.

Аналогичным подтверждением достоверности предположения относительно объемного механизма наработки синглетного кислорода при облучении образца ПТФЭ излучением оптического возбуждения может служить и температурная зависимость эффективности наработки синглетного кислорода, представленная на рис. 3 . 

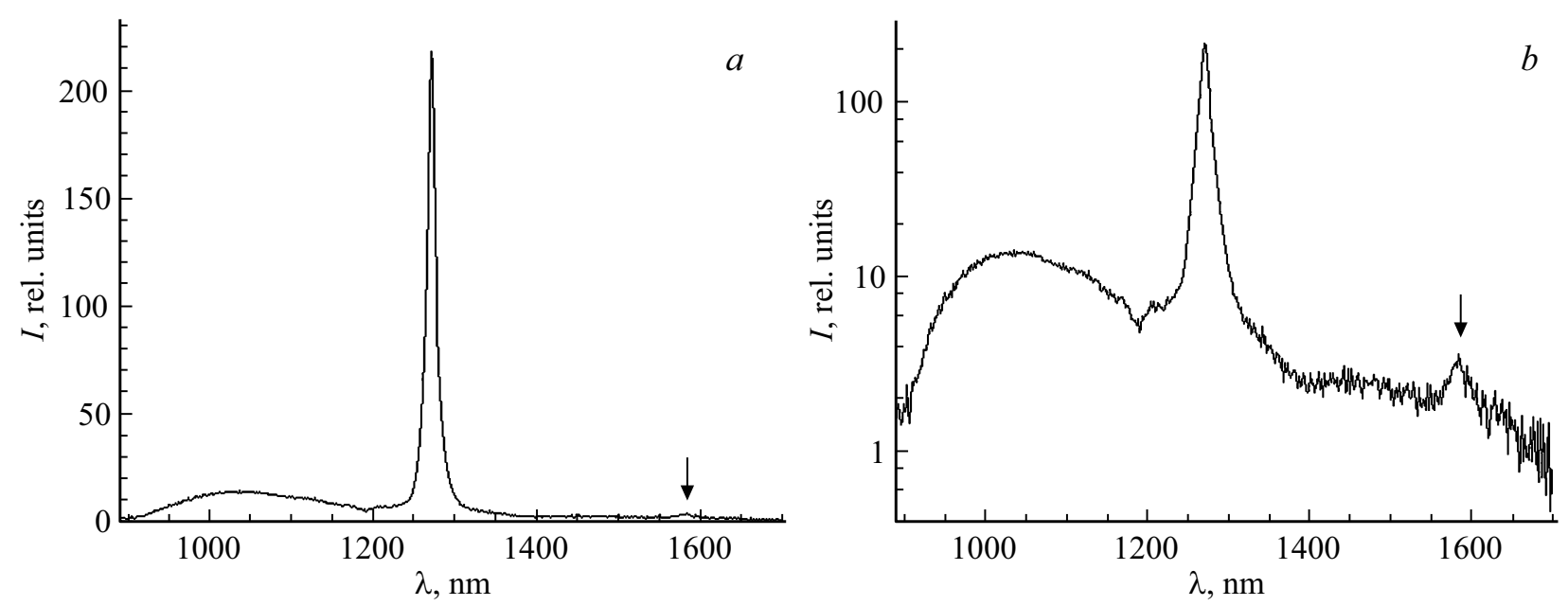

Рис. 4. Спектральный профиль фотолюминесценции синглетного кислорода из объема образца ПТФЭ в линейном $(a)$ и логарифмическом $(b)$ масштабах.

В соответствии с известной зависимостью растворимости газа в используемом растворителе от температуры, которая подчиняется закону Генри [21,22]

$$
k_{H} / k_{H}^{\theta}=\exp \left(\left(-\Delta H_{\text {soln }} / R\right)\left(1 / T-1 / T^{\theta}\right)\right)
$$

(где $\Delta H_{\text {soln }}$ - энтальпия раствора, $R$ - универсальная газовая постоянная, $T^{\theta}=298 \mathrm{~K}$ - комнатная температура, $k_{H}^{\theta}$ - концентрация растворенного газа при комнатной температуре, $k_{H}$ - концентрация растворенного газа при температуре $T$ ), при понижении температуры растворителя растворимость газа (в том числе и кислорода) в данном случае в ПТФЭ повышается. Повышение содержания кислорода в объеме ПТФЭ должно приводить к росту эффективности наработки синглетного кислорода, что и наблюдается на рис. 3. Понижение температуры растворителя, как известно [23], приводит к увеличению времени жизни возбужденного состояния кислорода в растворе, что также должно способствовать росту сигнала фосфоресценции синглетного кислорода из объема ПТФЭ. Для широкого спектра фотолюминесценции ПТФЭ с максимумом в районе $1.035 \mu \mathrm{m}$ влияние понижения температуры образца выражено очень слабо.

В условиях внешнего окружения молекул кислорода (с молекулами газа, растворителя или адсорбента) на интенсивность фосфоресценции синглетного кислорода преимущественное влияние оказывает спин-орбитальное взаимодействие молекулы кислорода с ее внешним окружением. При этом величина поглощения кислорода или, точнее, комплексов кислорода с внешним окружением заметно возрастает, как и интенсивность фотолюминесценции этих комплексов. Изучению влияния внешнего молекулярного окружения кислорода в газе или в конденсированной среде на параметры и свойства переходов из синглетных состояний кислорода в основное состояние посвящено большое количество как теоретических, так и экспериментальных работ [24-32]. При этом выполненные теоретические оценки [16-18] о возможности повышения излучательной вероятности переходов из синглетных состояний молекулы кислорода в основное под воздействием внешнего окружения получили убедительное экспериментальное подтверждение [27-32]. Образование этих комплексов влияет и на формирование спектрального профиля поглощения, индуцированного столкновениями с внешним окружением [33]. По-видимому, и в данном случае на достаточно интенсивную генерацию синглетного кислорода в объеме ПТФЭ оказывает внешнее окружение молекулы кислорода молекулярной структурой этого полимера.

Интересно отметить отдельные детали наблюдаемого спектрального профиля фотолюминесценции синглетного кислорода из объема образца ПТФЭ, которые характерны и для других условий генерации синглетного кислорода в растворах $[12,20,34]$ или, например, для жидкого кислорода [35]. Соответствующий профиль в линейном и логарифмическом масштабах для интенсивности излучения представлен на рис. 4 для образца ПТ$\Phi \ni$, изготовленного в Японии. Данный образец входит в качестве комплектующей детали в набор элементов ЭПР-спектрометра JES-ME-3X (Japan).

Наряду с основным максимумом фотолюминесценции на длине волны $1270.6 \mathrm{~nm}$ (переход $\left.{ }^{1} \Delta_{g}\left(v^{\prime}=0\right)^{-3} \Sigma_{g}\left(v^{\prime \prime}=0\right)\right)$ в представленном спектре присутствует и максимум на длине волны 1583.6 $\mathrm{nm}$ (отмечен стрелкой), соответствующий переходу ${ }^{1} \Delta_{g}\left(v^{\prime}=0\right)^{-3} \Sigma_{g}\left(v^{\prime \prime}=1\right)$, как это обычно наблюдалось при возбуждении кислорода в тетрахлорметане, или толуоле $[12,20,34]$, или в условиях жидкого кислорода [35]. Более отчетливо второй максимум виден на рис. $4, b$ с логарифмическим масштабом интенсивности излучения. Данный максимум можно заметить и на рис. 3 только с меньшей интенсивностью. По сравнению с тетрахлорметаном оба максимума смещены в коротковолновую область. Максимум на длине волны $1490 \mathrm{~nm}$, который наблюдался в 


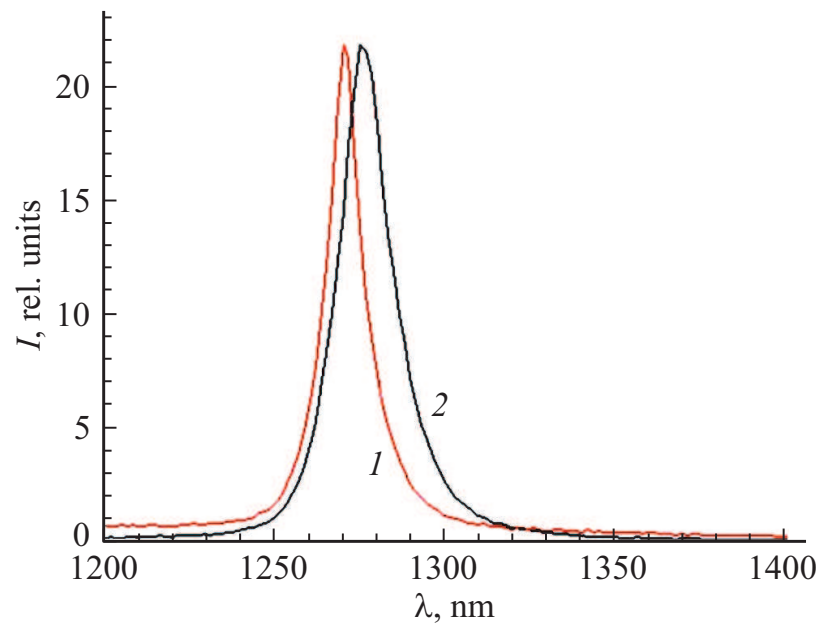

Рис. 5. Вид спектральных профилей фосфоресценции синглетного кислорода из объема ПТФЭ $(1)$ и из объема тетрахлорметана (2) при возбуждении на $\lambda=370 \mathrm{~nm}$.

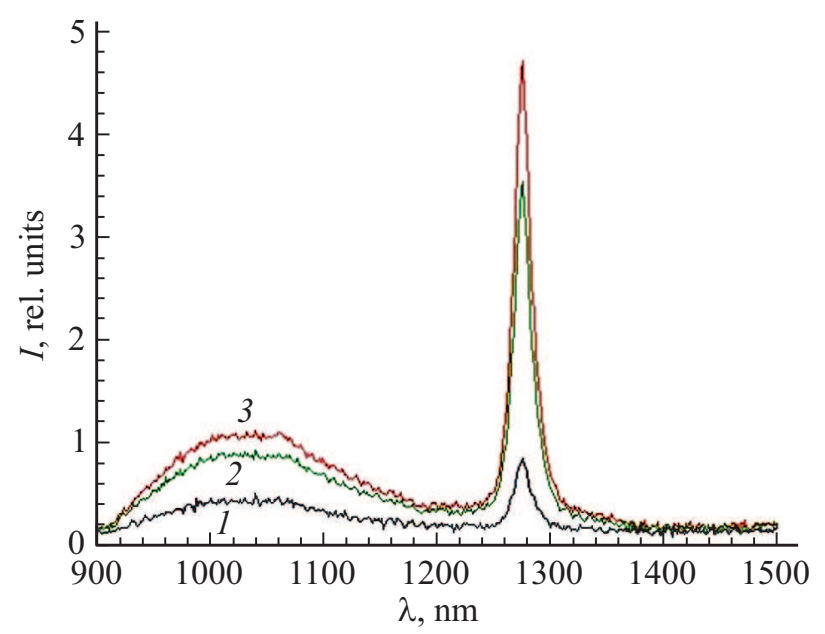

Рис. 6. Спектр фотолюминесценции синглетного кислорода из объема исходного растворителя $\mathrm{CCl}_{4}(1)$ и из суспензии порошка ПТФЭ в $\mathrm{CCl}_{4}$ после 7 (2) и после 8 дней (3).

работе [34] и был идентифицирован со стоксовой компонентой, индуцированной колебаниями $\mathrm{C}-\mathrm{F}-$ связи растворителя $\mathrm{C}_{10} \mathrm{~F}_{18}$ с частотой $1100 \mathrm{~cm}^{-1}$, в данном случае достаточно отчетливо не виден.

Как видно на рис. 5, максимум спектрального профиля фосфоресценции синглетного кислорода, наблюдаемого из объема ПТФЭ, не только смещен в коротковолновую область по сравнению с фосфоресценцией из объема тетрахлорметана, но и имеет более узкий профиль. Для удобства сравнения максимумы приведены к одинаковой интенсивности. Отмеченные закономерности, кстати, характерны для фторированных растворителей [12,36,37], включая сдвиг максимума в коротковолновую область и более узкий профиль фосфоресценции синглетного кислорода, особенно заметный, например, для $\mathrm{C}_{10} \mathrm{~F}_{18}$ [36].
В условиях ПТФЭ для кислорода, который находится в его объеме, по-видимому, образуются комплексы кислорода с внешним окружением, подобные тем, которые наблюдаются во фторированных растворителях. И этим могут объясняться наблюдающиеся аналогичные закономерности проявления фосфоресценции синглетного кислорода из объема ПТФЭ.

На рис. 6 на примере суспензии порошка ПТФЭ с размерами частиц $1-3 \mu \mathrm{m}$ (China) в химически чистом (ХЧ) тетрахлорметане $\left(\mathrm{CCl}_{4}\right)$ в дополнение к спектральным свойствам ПТФЭ продемонстрирована высокая сорбционная способность ПТФЭ, которая приводит к весьма заметной очистке исходного растворителя от присутствующих в нем загрязнений, понижая, таким образом, эффективность процессов тушения возбужденного состояния кислорода, что проявляется в существенном увеличении интенсивности генерации синглетного кислорода. В этом качестве известный сорбент $\mathrm{SiO}_{2}$ в аналогичных условиях показал заметно меньшую эффективность по очистке того же самого растворителя. Данное свойство высокой сорбционной способности суспензии наночастиц ПТФЭ (в том числе и в других средах, например в водной среде) может быть эффективно использовано в качестве элемента для доставки сенсибилизирующих лекарственных средств и синглетного кислорода к пораженной ткани в фотодинамической терапии, что уже активно исследуется [1-4].

\section{Заключение}

В работе проведено исследование фотолюминесценции в ближней ИК области спектра для нескольких произвольно выбранных образцов ПТФЭ (фторопласта) при их возбуждении ультрафиолетовым и видимым излучением. По своей конфигурации ПТФЭ представляет собой полукристаллический полимер, степень кристаллизации которого влияет на проницаемость и растворимость в нем газов. С увеличением степени кристаллизации (увеличение плотности с увеличением кристаллических доменов) проницаемость и растворимость газов уменьшаются [38], и, наоборот, с уменьшением степени кристаллизации увеличивается его пористость, а следовательно, растут проницаемость и растворимость газов. Поэтому проведенные исследования носят в определенной степени частный характер и не претендуют на широкое обобщение полученных результатов применительно ко всем конфигурациям структуры ПТФЭ.

В результате выполненного исследования фотолюминесценции образцов ПТФЭ в ближней ИК области спектра при его возбуждении ультрафиолетовым и видимым излучением показано, что в спектре фотолюминесценции, наблюдаемой с поверхности фторопласта при его возбуждении, наряду с широким спектром с максимумом в районе $1.035 \mu \mathrm{m}$ на общем спектральном профиле отчетливо присутствует характер- 
ный профиль люминесценции, совпадающий по своему положению со спектром фосфоресценции синглетного кислорода на длине волны $1270.6 \mathrm{~nm}$ (переход $\left.{ }^{1} \Delta_{g}\left(v^{\prime}=0\right)^{-3} \Sigma_{g}\left(v^{\prime \prime}=0\right)\right)$. В спектре присутствует и более слабый максимум на длине $1583.6 \mathrm{~nm}$, соответствующий переходу ${ }^{1} \Delta_{g}\left(v^{\prime}=0\right)^{-3} \Sigma_{g}\left(v^{\prime \prime}=1\right)$, который обычно наблюдается при возбуждении кислорода в тетрахлорметане или толуоле, а также в жидком кислороде.

На основе полученных результатов в работе сделано предположение, что фосфоресценция синглетного кислорода наблюдается из объема ПТФЭ при прямом оптическом возбуждении кислорода, сорбированного или растворенного в структуре ПТФЭ, по аналогии с прямым оптическим возбуждением кислорода в объеме различных растворителей. Более низкая по сравнению с растворителями интенсивность сигнала фосфоресценции синглетного кислорода из объема ПТФЭ (примерно втрое) объясняется более высокой прозрачностью растворителей и, очевидно, более высоким временем жизни синглетного кислорода в растворителях.

\section{Конфликт интересов}

Авторы заявляют, что у них нет конфликта интересов.

\section{Список литературы}

[1] Wilson S.R., Yurchenko M.E., Schuster D.I., Yurchenko E.N., Sokolova O., Braslavsky S.E., Gudrun Klihm. // J. Am. Chem. Sos. 2002. V. 124. N 9. P. 1977.

[2] Ghosh G., Minnis M., Ghogare A.A. // J. Phys. Chem. B. 2015. V. $119(10)$. P. 4155.

[3] Cardoso V.F., Correia D.M., Ribeiro C., Fernandes M.M., Lanceros-Méndez S. // Polymers. 2018. V. 10 (2). P. 161.

[4] Jia Lv, Yiyun Cheng. // Chem. Soc. Rev. 2021. V. 50. P. 5435.

[5] Scanni A., Valentini A., Perna G., Capozzi V., Convertino A. // J. Lumin. 2000. V. 91 (1-2). P. 87.

[6] Хатипов С.А., Нурмухаметов Р.Н., Селиверстов Д.И., Сергеев А.М. // Высокомолекулярные соединения. Серия А. 2006. Т. 48. № 2. С. 263.

[7] Khatipov S.A., Nurmukhametov R.N., Sakhno Yu.E., Klimenko V.G., Seliverstov D.I., Sychkova S.T., Sakhno T.V. // Nuclear Instruments and Methods in Physics Research B. 2011. V. 269. Iss. 21. P. 2600.

[8] Valenta J. // AIP Advances. 2018. V. 8. Iss. 10. P. 105123.

[9] Araujoa G.R., Pollmannb T., Ulrich A. // Eur. Phys. J. C. 2019. V. 79 (8). P. 653.

[10] Gao J., Ni Z., Liu Ya. // e-Polymers. 2016. V. 16 (2). P. 111.

[11] Alentiev A.Yu., Shantarovich V.P., Merkel T.C., Bondar V.I., Freeman B.D., Yampolskii Yu.P. // Macromolecules. 2002. V. 35. P. 9513.

[12] Киселев В.М., Багров И.В. // Опт. и спектр. 2017. Т. 123. № 4. C. 543; Kiselev V.M., Bagrov I.V. // Opt. Spectrosc. 2017. V. 123. N 4. P. 559.

[13] Yang M.K., French R.H., Tokarsky E.W. // J. Micro. Nanolith. MEMS MOEMS. 2008. V. 7(3). P. 033010.

[14] Tsai B.K., Allen D.W., Hanssen L.M., Wilthan B., Zeng Ji. // Proc. SPIE. 2008. V. 7065. P. 70650Y.
[15] Quill T., Weiss S., Hirschler C., Pankadzh V., DiBattista G., Arthur M., Chen Ja. // https://www.porex.com/wpcontent/uploads/2020/04/Ultraviolet-Reflectance-ofMicroporous-PTFE.pdf

[16] Киселев В.М., Кисляков И.М., Бурчинов А.Н. // Опт. и спектр. 2016. Т. 120. № 4. С. 545; Kiselev V.M., Kislyakov I.M., Burchinov A.N. // Opt. Spectrosc. 2016. V. 120. N 4. P. 520.

[17] Evstropiev S.K., Karavaeva A.V., Dukel'skii K.V., Kiselev V.M., Evstropyev K.S., Nikonorov N.V., Kolobkova E.V. // Ceramics International. 2017. V. 43. Iss. 16. P. 14504.

[18] Evstropiev S.K., Karavaeva A.V., Petrova M.A. Nikonorov N.V., Vasilyev V.N., Lesnykh L.L., Dukelskii K.V. // Mater. Today Commun. 2019. V. 21. P. 100628.

[19] Киселев В.М., Кисляков И.М., Багров И.В. // Опт. и спектр. 2016. Т. 120. № 6. С. 916; Kiselev V.M., Kislyakov I.M., Bagrov I.V. // Opt. Spectrosc. 2016. V. 120. N 6. P. 859.

[20] Киселев В.М., Багров И.В., Гренишин А.С. // Опт. и спектр. 2021. T. 129. № 4. C. 468; Kiselev V.M., Bagrov I.V., Grenishin A.S. // Opt. Spectrosc. 2021. V. 129. N 4. P. 506.

[21] Kretschmer C.B., Nowakowska J., Wiebe R. // Ind. Eng. Chem. 1946. V. 38 (5). P. 506.

[22] Perry's Chemical Engineers' Handbook. 7-th Ed. N.Y: McGraw_Hill, 1997.

[23] Багров И.В., Белоусова И.М., Данилов О.Б., Киселев В.М., Муравьева Т.Д., Соснов Е.Н. // Опт. и спектр. 2007. Т. 102. № 1. C. 58; Bagrov I.V., Belousova I.M., Danilov O.B., Kiselev V.M., Murav'eva T.D., Sosnov E.N. // Opt. Spectrosc. 2007. V. 102. N 1. P. 52.

[24] Минаев Б.Ф. // Изв. вузов. Сер. Физ. 1978. № 9. С. 115; Minaev B.F. // Izv. Vyssh. Uchebn. Zaved., Fiz. 1978. N 9. P. 115.

[25] Минаев Б.Ф. // Опт. и спектр. 1985. Т. 58. № 6. С. 1238; Minaev B.F. // Opt. Spectrosc. 1985. V. 58. N 6. P. 1238.

[26] Klotz R., Peyerimhoff S.D. // Molecular Phys. 1986. V. 57. N 3. P. 573.

[27] Ogilby P.R., Foote Ch.S. // J. Am. Chem. Soc. 1983. V. 105. N 11. P. 3423.

[28] Scurlock R.D., Ogilby P.R. // J. Phys. Chem. 1987. V. 91. P. 4599.

[29] Schmidt R., Afshari E. // J. Phys. Chem. 1990. V. 94. P. 4377.

[30] Schweitzer C., Schmidt R. // Chem. Rev. 2003. V. 103. P. 1685.

[31] Jensen R.L., Holmegaard L., Ogilby P.R. // Phys. Chem. B. 2013. V. 117. N 50. P. 16227.

[32] Bregnhoj M., Ogilby P.R. // J. Phys. Chem. A. 2015. V. 119. N 35. P. 923.

[33] Bregnhoj M., Westberg M., Minaev B.F., Ogilby P.R. // Acc. Chem. Res. 2017. V. 50. N 8. P. 1920.

[34] Chou Pi-Tai, Khan A.U. // Chem. Phys. Lett. 1984. V. 103. N 4. P. 281.

[35] Багров И.В., Гоголева Н.Г., Гренишин А.С., Киселев В.М. // Опт. и спектр. 2020. Т. 128. № 1. С. 58; Bagrov I.V., Gogoleva N.G., Grenishin F.S., Kiselev V.M. // Opt. Spectrosc. 2020. V. 128. N 1. P. 57.

[36] Macpherson A.N., Truscott T.G., Turner P.H. // J. Chem. Soc. Faraday Trans. 1994. V. 90 (8). P. 1065.

[37] Багров И.В., Киселев В.М., Кисляков И.М., Соснов Е.Н. // Опт. и спектр. 2014. Т. 116. № 4. С. 609; Bagrov I.V., Kiselev V.M., Kislyakov I.M., Sosnov E.N. // Opt. Spectrosc. 2014. V. 116. N 4. P. 567.

[38] Graunke T., Schmitt K., Raible S., Wöllenstein Jü. // Sensors. 2016. V. 16 (10). P. 1605. 